\title{
Chronic ventricular pacing in children: toward prevention of pacing-induced heart disease
}

\author{
Irene E. van Geldorp • Ward Y. Vanagt • \\ Frits W. Prinzen • Tammo Delhaas
}

Published online: 24 November 2010

(C) The Author(s) 2010. This article is published with open access at Springerlink.com

\begin{abstract}
In children with congenital or acquired complete atrioventricular (AV) block, ventricular pacing is indicated to increase heart rate. Ventricular pacing is highly beneficial in these patients, but an important side effect is that it induces abnormal electrical activation patterns. Traditionally, ventricular pacemaker leads are positioned at the right ventricle (RV). The dyssynchronous pattern of ventricular activation due to $\mathrm{RV}$ pacing is associated with an acute and chronic impairment of left ventricular (LV) function, structural remodeling of the LV, and increased risk of heart failure. Since the degree of pacing-induced dyssynchrony varies between the different pacing sites, 'optimal-site pacing' should aim at the prevention of mechanical dyssynchrony. Especially in children, generally paced from a very early age and having a perspective of life-long pacing, the preservation of cardiac function during chronic ventricular pacing should take high priority. In the perspective of the (patho)physiology of ventricular pacing and the importance of the sequence of
\end{abstract}

I. E. van Geldorp $(\varangle)$ · W. Y. Vanagt · F. W. Prinzen Department of Physiology, Cardiovascular Research Institute Maastricht (CARIM), Maastricht University, P.O. Box 616, 6200 MD Maastricht, The Netherlands

e-mail: i.vangeldorp@maastrichtuniversity.nl

I. E. van Geldorp · W. Y. Vanagt · T. Delhaas

Department of Pediatrics, Maastricht University Medical Center, Maastricht, The Netherlands

W. Y. Vanagt

Department of Pediatric Cardiology, University Hospital

Gasthuisberg Leuven, Leuven, Belgium

T. Delhaas

Department of Biomedical Engineering, Cardiovascular Research Institute Maastricht (CARIM), Maastricht University, Maastricht, The Netherlands activation, this paper provides an overview of the current knowledge regarding possible alternative sites for chronic ventricular pacing. Furthermore, clinical implications and practical concerns of the various pacing sites are discussed. The review concludes with recommendations for optimalsite pacing in children.

Keywords Pacing · Pediatrics - Dyssynchrony · Ventricular · Prevention

\section{Introduction}

While the majority of patients receiving pacemakers are adults at usually advanced age, a small group of pacemaker recipients are children, even newborns. Results and conclusions from pacing studies in adults are not readily transferable to the pediatric population, because diseases and causes of dyssynchrony and heart failure differ strongly. In adults, indication for pacemaker therapy or cardiac resynchronization therapy (CRT) concerns, among others, bradycardia, left ventricular (LV) dysfunction, and dyssynchrony due to partially diseased conduction systems often combined with degenerative diseases and infarctions of the myocardium. In children, it typically concerns bradycardia due to complete atrioventricular (AV) conduction block, usually associated with healthy myocardium. Albeit AV block may exist "isolated" in structurally normal hearts, in children and young adults AV block is often combined with abnormalities in cardiac anatomy. In structurally normal hearts, AV block may either be congenitally induced by maternal autoantibodies (e.g., antiSSA (Ro), anti-SSB (La)) or be acquired by infectious diseases or progressive AV-conduction tissue fibrosis. In children with structural congenital heart disease, AV block 
may either be associated with the structural disease itself or be induced by surgical or percutaneous procedures performed.

In patients with complete AV block and bradycardia, ventricular pacing is indicated to increase heart rate, rather than to 'resynchronize' electrical activation. In addition to the obvious beneficial effects of the restoration of heart rate, the unpredictable risk of sudden cardiac death as well as LV failure associated with untreated complete heart block is cured by chronic ventricular pacing [1, 2]. Therefore, AV block associated with symptomatic bradycardia is a class I indication for ventricular pacing therapy [3]. Despite the fact that ventricular pacing is highly beneficial in patients with completely blocked intrinsic conduction, it does not resemble nature. In contrast, ventricular pacing induces an abnormal electrical activation pattern, which may cause mechanical dyssynchrony, associated with impairment of pump function, LV remodeling, and increased risk of heart failure [4-10]. Right ventricular (RV) pacing, rather than etiology of AV block, has even been identified as an independent risk factor for the development of LV dilatation and dysfunction following chronic pacing $[11,12]$. In deduction, in patients with complete heart block requiring chronic ventricular pacing, the prevention of mechanical dyssynchrony and thus the prevention of functional as well as structural deterioration seem a major challenge in addition to the restoration of heart rate. Especially in children, generally paced from a very early age and typically having normal myocardial function at the initiation of pacing, as well as having a perspective of life-long pacing, the preservation of cardiac function during chronic ventricular pacing should take high priority.

The objectives of this paper are (1) to elucidate the importance of the sequence of activation in the pathophysiology of ventricular pacing, (2) to review several sites for chronic ventricular pacing, (3) to discuss clinical implications of the various sites for ventricular pacing in children, and (4) to give recommendations for optimal-site pacing in children.

\section{(Patho)physiological background of ventricular pacing}

\section{Normal electrical activation}

Under physiological circumstances, the electrical impulse given by the sinus node is transmitted to the AV node and is then rapidly conducted, via the specialized His-Purkinje conduction system, to both ventricles simultaneously resulting in 'synchronous' electrical activation of the heart. Literally, "synchronous activation" denominates simultaneous activation of all ventricular myocytes, which is not achieved under physiological circumstances. Despite the rapid propagation $(3-4 \mathrm{~m} / \mathrm{s})$ of the electrical impulse through the conduction tissue, activation of the ventricles occurs over a certain amount of time. Normally, electrical activation starts at the endocardium of the apex and progresses toward the epicardium, as well as upwards to the base, resulting in a coordinated and energetically efficient mechanical contraction, which is crucial for optimal LV performance. Therefore, the term "euchrony" would more correctly describe the normal timing and sequence of ventricular activation under physiological conditions. However, "electrical synchrony" and "synchronous activation" are generally used in the literature to denominate the physiological timing and sequence of electrical activation and are accordingly used throughout this paper. During normal activation, synchrony is observed between the ventricles (interventricular synchrony) and within each ventricle (intraventricular synchrony). LV-intraventricular electrical synchrony during normal activation is illustrated by the left upper panel of Fig. 1 .
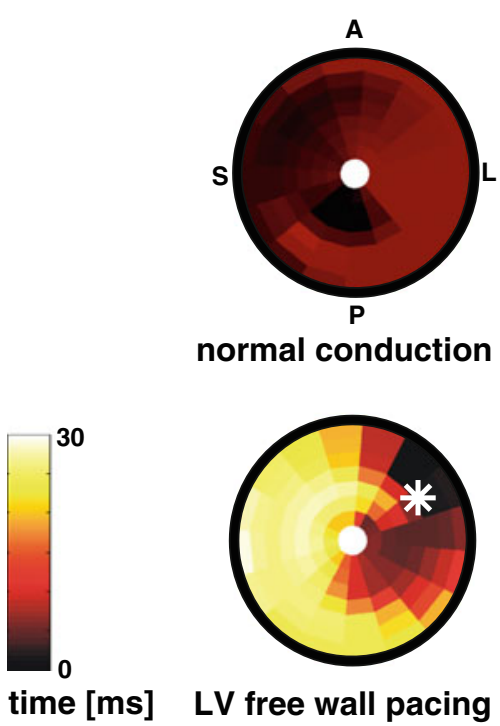

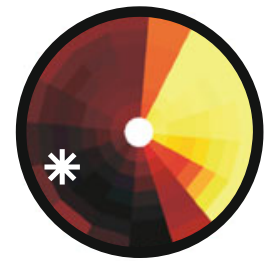

RV apical pacing

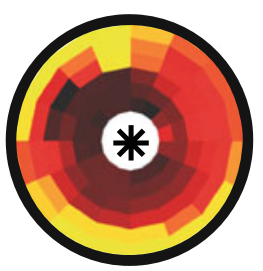

LV apical pacing
Fig. 1 Left ventricular endocardial activation in canine hearts. Electrical activation mapping using a left ventricular (LV) intraventricular mapping catheter in canine experiments (described by Verbeek et al. JACC 2003), during normal activation, pacing from the right ventricular (RV) apex, LV free wall, and LV apex, respectively. The electrical activation maps are presented as bull's eye plots with the inner disk representing the LV apex and the outer disk representing the $\mathrm{LV}$ base. The letters $\mathrm{A}, \mathrm{P}, \mathrm{S}$, and $\mathrm{L}$ indicate the anterior, posterior, septal, and lateral wall, respectively. Electrical activation of the LV is fast and synchronous during normal activation. During ventricular pacing, the region in the proximity of the pacing site is early-activated, whereas myocardium remote from the pacing site is late-activated. In LV apical pacing, electrical activation is circumferentially synchronous. $*=$ ventricular pacing site 
Pathophysiology of ventricular pacing

During ventricular pacing, the initiation and the sequence of electrical ventricular activation are different from those in normal physiological circumstances. From the site of pacing, the electrical activation wave spreads over the ventricles through the slowly transmitting myocardium, instead of through the rapidly conducting specialized conduction system. Slow cell-to-cell transmission of the electrical impulse results in asynchrony of electrical ventricular activation, with early activation of the myocytes close to the pacing site and delayed activation of the cells in remote regions (Fig. 1). Consequently, early systolic shortening of the early-activated myocytes results in stretch of late-activated myocytes, rather than that it results in the onset of the ejection phase. When myocytes in remote regions are subsequently activated and start to contract, they contract even more powerfully due to the early systolic pre-stretching (known as the local Frank-Starling mechanism) [4]. Hence, electrical asynchrony, as induced by ventricular pacing, results in a dyssynchronous contraction pattern. The mechanical dyssynchronous contraction pattern is associated with a reduction in LV pump function by an asymmetric redistribution of mechanical workload in the myocardium, which in turn results in a redistribution of oxygen demand and perfusion, as well as in asymmetrical hypertrophy [13-16].

Since the degree of pacing-induced dyssynchrony varies between the different pacing sites (Fig. 1), the site for chronic ventricular pacing should be carefully selected, so that adverse mechanical dyssynchronization is minimized. In order to propose which site(s) may be optimal for chronic ventricular pacing in children, it is necessary to critically appraise the various pacing sites in the context of mechanical activation patterns and cardiac function.

\section{Ventricular pacing sites}

Conventional pacing sites: right ventricular apex and free wall

Traditionally, ventricular pacemaker leads are positioned at the RV. The RV apex and free wall are easily accessible, either at the epicardium via a surgical implantation or at the endocardium by means of a transvenous approach. These RV pacing sites are readily identified and associated with stable lead position and reliable chronic pacing parameters (e.g., capture). However, chronic RV pacing is associated with deleterious effects in functional and structural outcome [5-10]. In hearts with normal left-right anatomy, during RV pacing, a left bundle branch block (LBBB) pattern of activation is created $[4,7,17,18]$. This pattern is characterized by early activation of the RV and septum and delayed activation of the LV lateral wall, implicating electrical and mechanical asynchrony between the ventricles (interventricular asynchrony), as well as within each ventricle (intraventricular asynchrony). Since the RV free wall starts to contract before the interventricular septum and the LV free wall, RV pressure increases before $\mathrm{LV}$ pressure is built up. As a consequence of this abnormal early systolic pressure gradient over the interventricular septum, the septum bulges into the LV, which can be observed as paradoxical movement of the septum [19].

Although the dyssynchronous pattern of ventricular activation due to $\mathrm{RV}$ pacing is well tolerated in most children [20, 21], several studies have shown that this pattern is associated with an acute and chronic impairment of $\mathrm{LV}$ function, structural remodeling of the $\mathrm{LV}$, and increased risk of heart failure $[5,6,22]$. Though overt heart failure is reported in about $7 \%$ and impaired $\mathrm{LV}$ function in up to $13 \%$ of the chronically RV-paced pediatric patients after follow-up for about one decade [5, 10, 12, 20], the actual incidence of ventricular dysfunction in relation to chronic RV pacing remains undefined and may be even higher for life-long follow-up.

The recognition of the potentially deleterious effects of $\mathrm{RV}$ pacing has initiated the search for alternative sites for chronic ventricular pacing. In addition to the traditional RV apex and free wall sites, several other sites within the RV became accessible by advances in pacemaker-lead technology and implant approaches and began to be clinically explored. Also, biventricular pacing has been introduced in children, which can be achieved by the insertion of an additional lead at the LV epicardium (either transvenously throughout the coronary sinus or surgically). Usually, surgical approaches are preferred for all lead implantation in small children or children undergoing cardiac surgery, implicating that there is to a great extent freedom to position the lead at the epicardium of either the RV, or the $\mathrm{LV}$, or even at both.

\section{Alternative-site RV pacing}

Both terms 'alternative-site $R V$ pacing' and 'selective-site $R V$ pacing' refer to pacing at sites other than the $\mathrm{RV}$ apex or free wall, though either located within or approached via the RV. These sites are selected based on the (individual) prospect of a more physiological electrical activation pattern and a better hemodynamic response with less detrimental remodeling.

By lead insertion through the RV, the His bundle may be paced directly in order to restore the normal pathway of electrical conduction system. In patients without distal conduction abnormalities, His-bundle pacing would obviously induce a normal physiological sequence of activation 
and therefore prevent the heart from dyssynchronous activation and the harmful effects associated. Indeed, beneficial effects of successful His-bundle pacing have been reported in adults with AV-nodal ablation for atrial fibrillation [23, 24]. Although technical advances have improved the success rate of His-bundle pacing [25], implantation in this very small region is a challenging procedure and seems not very applicable in children. Moreover, especially in children with surgically induced AV block, but also in children with congenital AV block, the His bundle may be involved in the pathological interruption of the conduction system, implicating that there is no rationale left for direct His-bundle pacing.

Within the field of research on alternative RV pacing sites, also the $R V$ outflow tract has been extensively investigated. Unfortunately, the term RV outflow tract pacing is not always clearly defined in literature and has been used to describe a variety of RV pacing sites, including the true outflow tract and mid-septum. Nonetheless, the differentiation between the diverse sites within the conical RV outflow tract is very important, as activation patterns and wave propagation will differ depending on the exact anatomical position of the lead [26, 27]. Not surprisingly, studies with regard to the effects of RV outflow tract pacing without specification of exact anatomical definition of the site have shown inconsistent results [28, 29]. Most consistently, beneficial effects for RV outflow tract pacing have been found in studies clearly mentioning to pace from the septal side of the RV outflow tract (also defined as "high septal" or "para-Hisian" pacing) [22, 3035]. Thus, in RV outflow tract pacing in particular, the septal side of the outflow tract may be a target. Nevertheless, it should be noted that 'septal RV outflow tract' is not a good definition, since the upper part of the 'septal side' within the RV outflow tract is located above the LV. Therefore, only the inferior part of the septal side of the $R V$ outflow tract can be considered as truly septal and may be the preferred location for lead placement in the RV outflow tract $[26,27]$.

\section{Biventricular pacing}

The concept of biventricular pacing is to synchronize electrical and mechanical activation by electrical stimulation of both ventricles. Biventricular pacing is mainly applied in adult heart failure patients with normal cardiac anatomy, suffering from LV dysfunction in association with LV dyssynchrony due to intrinsic LBBB. Since in these patients, biventricular pacing is applied in order to resynchronize electrical activation, it is often defined as "cardiac resynchronization therapy" (CRT).

Numerous studies have indicated that in the majority of the adult patients with heart failure and conduction system disease, biventricular pacing improves LV function and reverses LV remodeling as well as that it reduces clinical symptoms and decreases mortality [36-38]. Based on the rationale that the sequence of activation in $R V$ pacing is similar to the activation pattern in LBBB, application of biventricular pacing has been extended to heart failure patients with RV-pacing-associated dyssynchrony. Indeed, also in patients with a history of chronic RV pacing and mild to severe cardiomyopathy, biventricular pacing is beneficial concerning LV geometry and function, as well as regarding clinical symptoms [39-42].

The data from large randomized adult CRT trials cannot simply be translated to children with cardiac failure, because the pediatric population not only includes children with normal cardiac anatomy and LV failure but also includes children with univentricular hearts (with either RV or LV morphology), hearts with a systemic RV (i.e., heart with either congenitally corrected transposition of the great arteries or transposition of the great arteries with atrial switch procedure in the past), and hearts with RV failure (e.g., RV failure associated with corrected tetralogy of Fallot). In addition, a substantial number of pediatric CRT candidates have ventricular dyssynchrony and cardiac failure related to conventional pacemaker therapy for postoperative or congenital AV block. Nonetheless, encouraged by the positive results in adults, biventricular pacing meanwhile has also been applied in children with ventricular dysfunction. In these children, with either isolated AV block or AV block combined with structural heart disease, biventricular pacing (often following chronic RV pacing) improved pump function and reversed ventricular remodeling. Upgrade from single-site RV pacing to biventricular pacing was at least as effective as in upgrade to biventricular pacing in adults with heart failure, and in some children, the need for cardiac transplantation was even deferred [43, 44]. From the analysis of Janousek et al., the response to biventricular pacing seems to be dependent on the structural and pathophysiological substrate, being most favorable after upgrades from single-site RV pacing to biventricular pacing in patients in whom the LV is the systemic ventricle [44]. Noteworthy, in these studies, resynchronization was mostly indicated for decreased LV function following chronic conventional RV pacing [44, 45]. Although biventricular pacing is better in comparison with RV pacing, it may not be as good as normal intrinsic activation in healthy hearts $[46,47]$.

Single-site left ventricular pacing

Comparable to that of upgrade to biventricular pacing, in children with LV dysfunction after chronic RV pacing, functional improvement and reverse remodeling are reported for $L V$ single-site pacing [48, 49]. Although 
important, this finding was not very surprisingly as LV pacing had already been shown to acutely increase pump function when compared with RV pacing in laboratory dogs and in children undergoing cardiac surgery [17]. In dogs with experimental complete AV block, Mills and colleagues showed that LV apical and LV septal pacing resulted in only moderate electric desynchronization as well as in minor redistribution of mechanical work and perfusion [50]. Even after 4 months of pacing in these dogs, LV pacing induced normal levels of contractility, relaxation, and myocardial efficiency. Moreover, singlesite LV apical and LV septal pacing maintained normal cardiac function and efficiency, at least as well as biventricular pacing [50]. In line with these findings, in adult heart failure patients, single-site LV pacing resulted in the same improvement in LV function as during acute or chronic biventricular pacing [51-53]. It is argued that single-site LV pacing in LBBB patients results in "hidden resynchronization" by fusion of the activation front originating from the left lateral pacing electrode with the impulse traveling through the right bundle. However, benefits of single-site LV pacing are observed during pacing with short AV delays [53] and in patients with atrial fibrillation [52], making the hypothesis of "hidden resynchronization" very unlikely to be applied for all patients.

We postulate that, above and beyond synchrony, the sequence of activation is a major determinant of cardiac pump function $[4,54]$. During LV (free wall) pacing, the prolonged duration of total activation is comparable with the delay during RV pacing, which is reflected by a similar prolongation of the QRS duration [55]. However, during $\mathrm{LV}$ pacing, the LV lateral wall is activated prior to the septum and RV lateral wall, preventing the septum from paradoxical movements and resulting in superior hemodynamic performance when compared to RV pacing [19]. On top of that, a physiological apex-to-base sequence of activation is induced by LV apical pacing, which results in synchronous electrical activation and contraction at the circumferential level of the LV (Fig. 1) [46, 47]. This hypothesis is supported by the observation of Gebauer et al. that $\mathrm{LV}$ apical pacing, compared with other sites, preserves septal to lateral LV synchrony and systolic function [56], as well as by other studies showing that LV apical pacing maintains cardiac function at a normal level $[17,50]$.

In some centers, based on surgical preferences, chronic single-site LV pacing has been applied in children for already several years [57]. Small studies in children of one of these centers show that chronic LV free wall pacing may preserve LV function and LV dimension at a level of healthy controls $[49,55,58]$. Currently, a multicenter study is carried out to retrospectively and cross-sectionally evaluate long-term influences of various pacing sites on LV function and dyssynchrony in structurally normal hearts.
Preliminary results from this study indicate that single-site $\mathrm{LV}$ pacing results in better $\mathrm{LV}$ function and mechanical synchrony when compared to RV pacing $[59,60]$.

\section{Clinical implications and practical considerations}

In children, resynchronization of dyssynchrony induced by $\mathrm{RV}$ pacing, or, preferably, prevention of mechanical dyssynchrony (in case of 'de novo pacing'), must take high priority. Biventricular pacing, as well as single-site LV apical and LV free wall pacing seem all promising in the young, concerning preservation and restoration of pump function. This raises the question whether or not such pacing therapies should be applied in all children with an indication for chronic ventricular pacing.

Individual approach for optimal pacing sites

Although complete AV block is often combined with structural heart defects, only children with an isolated heart block were included in most studies concerning the effects of various pacing sites. The ever-improving survival after surgery for complex congenital heart disease broadens the variety of anatomical substrates and indications for chronic ventricular pacing. Thus, the pediatric pacing population is highly heterogeneous in terms of age and cardiac anatomy. This implicates that findings from studies in adults or children with structurally normal hearts cannot easily be extrapolated to the entire pediatric pacing population. Therefore, an individual approach may be the best way to identify the "optimal pacing site".

It seems reasonable to assume that in patients with abnormal anatomy or cardiac function, the optimal sequence of activation may be different from the optimal sequence of activation in anatomically normal hearts. Indeed, in patients with RBBB and RV failure after surgically repaired tetralogy of Fallot, RV pacing has been proposed as a potential therapy for RV failure [61-63]. Nevertheless, other studies on effects of pacing sites in these patients suggested that, when both RV and LV function are concerned, biventricular pacing may be superior to RV pacing [64, 65]. Further investigations are required to confirm these findings and to determine whether pacing the late-activated ventricle (i.e., RV) or biventricular pacing in these patients is worthwhile [66].

Although upgrade to biventricular pacing seemed to be most favorable in patients in whom the LV is the systemic ventricle [44], the beneficial effects of biventricular and single-site LV pacing have been observed in a mixed pediatric population [12, 43-45].

Especially in children with abnormal cardiac anatomy, influences of different pacing sites on cardiac function are 
not well known. To find the optimal pacing site in children with abnormal anatomy, various pacing sites should be individually investigated for their effects on electrical activation and cardiac function. Given the absence of a consistent correlation between cardiac function and paced QRS duration in acute and chronic pacing studies, we discourage the use of QRS duration as a tool for the selection of an optimal epicardial pacing site in children $[17,55,67,68]$. A better approach in this respect may be the use of ECG imaging, which noninvasively images electrical activation patterns [69, 70], although the optimal activation pattern for the diverse anatomical substrates is not known yet. Therefore, and since the intention of optimal-site pacing is to preserve cardiac function, it may be even better to measure pump function by either (noninvasive) hemodynamic or echocardiographic parameters while pacing from various pacing sites, and implant the lead at the site where pacing results in the best pump function.

\section{Practical considerations}

In addition to functional rationales behind ventricular lead positions, practical aspects should be taken into account when choosing the optimal site of pacing for rate control in the individual patient. First of all, in children with (complex) congenital heart defects, restrictions in lead placement could be introduced by anatomy, prior surgery or scarred myocardium. Secondly, a major practical advantage of single-site pacing, compared with biventricular pacing, is that only one ventricular lead is needed, prolonging battery longevity and reducing potential vascular problems and lead-associated complications. Because every (re)placement of either a lead or generator comes with risks of complications, the number of replacements should be minimized, especially in children, since they have a perspective of life-long follow-up. Thus, single-lead pacing should be seriously considered.

With respect to the technique of lead positioning, in older children and adult patients, leads are often transvenously inserted and endocardially positioned at the RV apex or septum, because it is technically safe, fast, and reliable. In neonates and small children, most centers preferably use epicardial lead placement by a surgical approach. Epicardial lead placement is also preferred in children with an open connection to the systemic ventricle, because the presence of endocardial leads increases the risk of embolism. Since possibly successful alternative RV pacing sites require a transvenous approach for lead implantation, these sites are probably not feasible in small children. For the purpose of single-site LV pacing, the epicardial LV apex or, alternatively, the LV free wall can easily be approached through a (limited) sternotomy, sub-xiphoidal incision or left lateral thoracotomy [57], with good lead stability and pacing performance, as well as excellent cosmetic results. In larger children and adults, in whom a transvenous approach may be preferred, single-site LV pacing might also be achieved by implantation via the coronary sinus, though for single-site LV pacing, it is recommended to position the ventricular lead as far to the apex as possible [17, 55]. Future perspectives for lead insertion for LV pacing are a trans-septal approach to endocardial LV septal pacing sites [50] and "wireless" pacing $[71,72]$. As soon as both are clinically applicable, pacing could be achieved from any of the diverse endocardial sites in the systemic ventricle.

\section{Recommendations for optimal pacing in children}

Based on the (patho)physiological background of ventricular pacing and the current knowledge regarding the various pacing sites, as well as on clinical and practical aspects, we would like to give recommendations for optimal pacing in children. Our recommendations and suggestions for pacing in children with normal cardiac anatomy and structural heart defects are schematically displayed in Fig. 2a and b, respectively.

First of all, because by definition, ventricular pacing alters the physiological pattern of electrical activation, ventricular pacing should be avoided (or minimized) in patients with (partially) preserved AV conduction and intact His-Purkinje system, such as sick sinus syndrome $[73,74]$. Also, in children with chronic ventricular pacing for surgically induced AV block, the existence of underlying ventricular rhythm by re-established AV conduction should be regularly checked, as very late recovery of AV conduction is reported to occur [75].

In children with $\mathrm{AV}$ block and structurally normal hearts, we advocate the use of single LV apex and LV free wall sites as the preferred sites for ('de novo') chronic ventricular pacing $[55,58-60,76]$. It is recommended to preferably avoid pacing from the RV free wall [12]. However, in young adults receiving a first pacing system or having a system replacement, the routine transvenous approach seems justifiable in the context of practical aspects, since RV apical pacing is well tolerated by most patients $[20,21]$ and since change to single-site LV pacing, as well as upgrade to biventricular pacing, induces reversal of remodeling and reversal of the impaired LV function in deteriorated hearts after pacing [41, 43, 44, 48, 49].

Regular echocardiographic checkup is warranted in all pediatric patients with pacemaker therapy, and especially in children who are paced at the RV. Changing the site of pacing to either biventricular or single-site pacing at the 


\section{(A)}

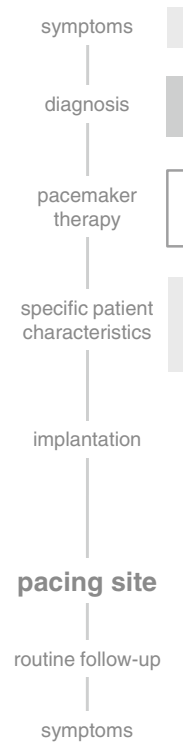

ventricular pacing in children with normal cardiac anatomy

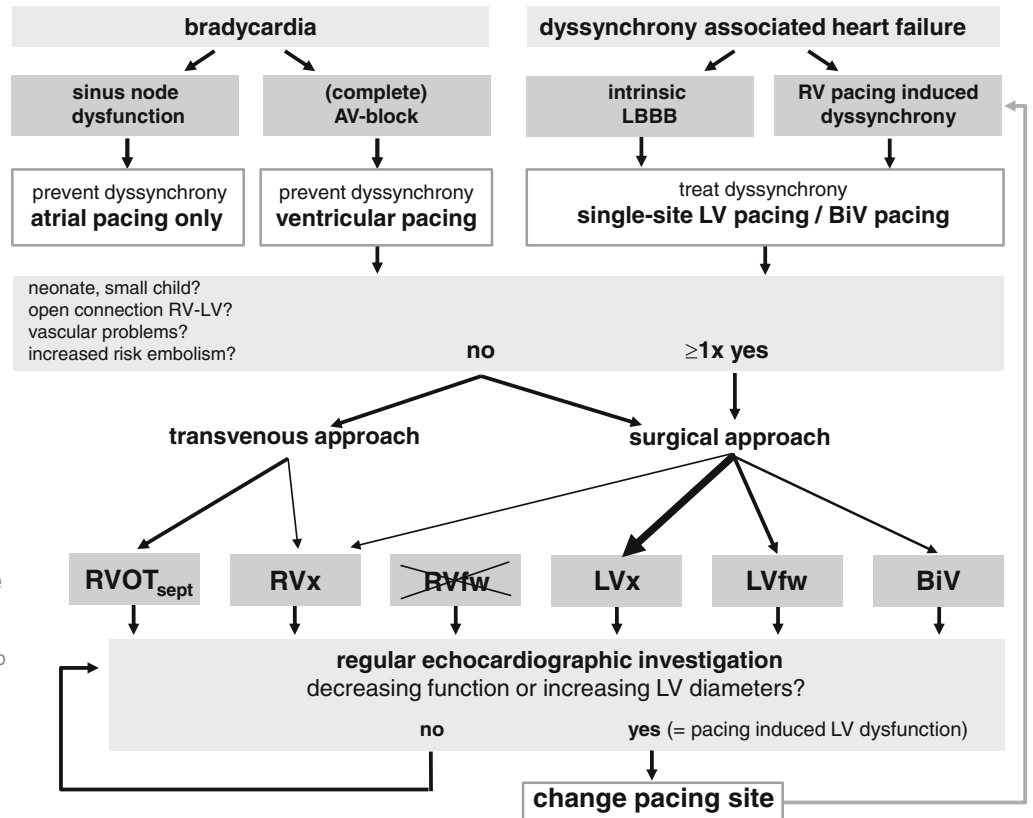

ventricular pacing in children with structural heart defects

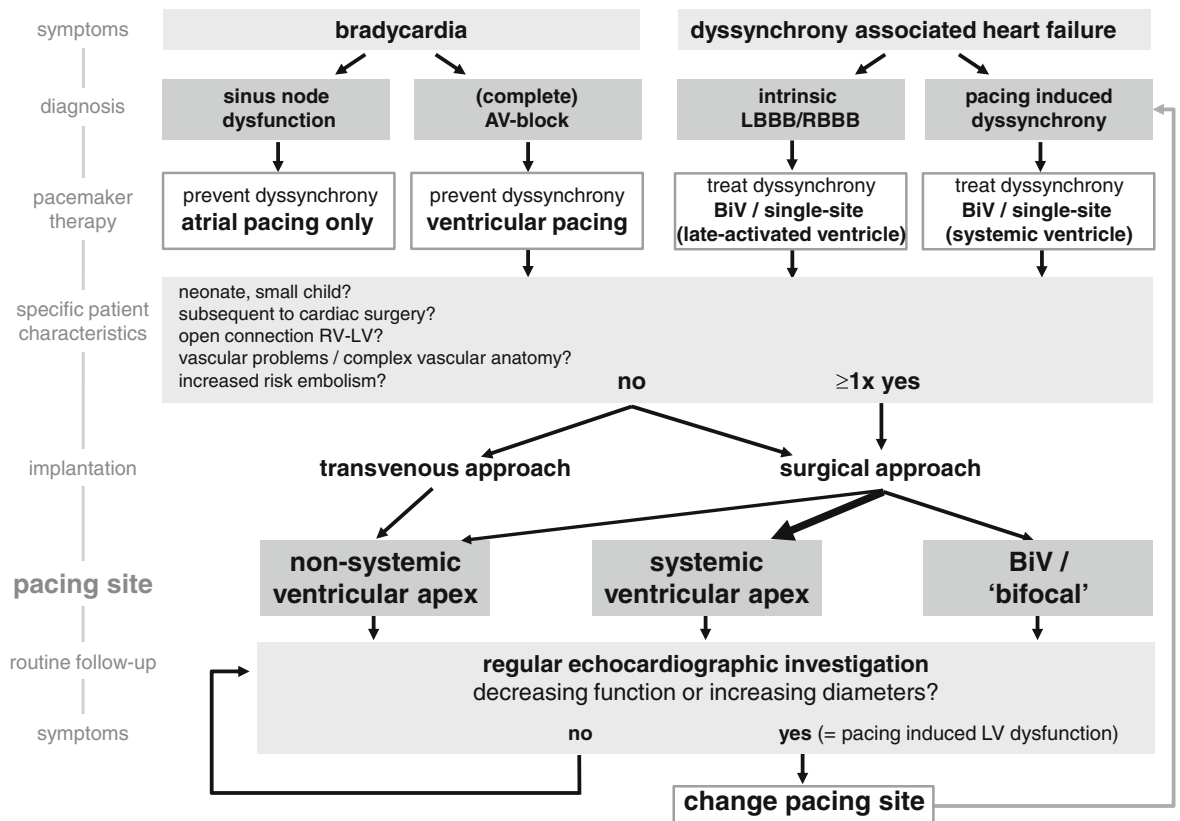

Fig. 2 Recommendations for optimal pacing in children; a schematic overview. An individual approach may be the best way to identify the "optimal pacing site". In order to choose the optimal pacemaker therapy for the individual patient, one should discriminate between pacing approaches aiming at the prevention of dyssynchrony and the ones that resynchronize (treat dyssynchrony). In children with AV block and normal cardiac anatomy, (a) we advocate the use of single LV apex and LV free wall sites as the preferred sites for chronic ventricular pacing. In young adults, the routine transvenous approach to the RV apex seems justifiable in the context of practical aspects. It is recommended to avoid pacing from the RV free wall, both endocardially and epicardially. In children with structural heart defects, (b) we suggest to implant the lead for chronic ventricular pacing preferably at the systemic ventricle if a surgical approach is also practically advised. Regular echocardiographic checkup is warranted in all pediatric patients with pacemaker therapy. Changing the site of pacing to either biventricular or single-site pacing should be considered as soon as echocardiography reveals signs of ventricular dilatation or dysfunction. $A V$ block atrioventricular block, $L V$ left ventricle/ventricular, $R V$ right ventricle/ventricular, $L B B B$ left bundle branch block, $R B B B$ right bundle branch block, $R V O T_{\text {sept }}$ the inferior part of the septal side of the $\mathrm{RV}$ outflow tract, $R V f w$ RV free wall, $R V x \mathrm{RV}$ apex, $L V x \mathrm{LV}$ apex, $L V f w$ LV free wall, $B i V$ biventricular RVx (or RVfw) + LVfw. *leads should be placed preferably at the ventricular apex 
systemic ventricle should be considered as soon as echocardiography reveals signs of ventricular dilatation or dysfunction.

Open Access This article is distributed under the terms of the Creative Commons Attribution Noncommercial License which permits any noncommercial use, distribution, and reproduction in any medium, provided the original author(s) and source are credited.

\section{References}

1. Udink ten Cate FE, Breur JM, Cohen MI, Boramanand N, Kapusta L, Crosson JE, Brenner JI, Lubbers LJ, Friedman AH, Vetter VL, Meijboom EJ (2001) Dilated cardiomyopathy in isolated congenital complete atrioventricular block: early and longterm risk in children. J Am Coll Cardiol 37(4):1129-1134

2. Michaelsson M, Riesenfeld T, Jonzon A (1997) Natural history of congenital complete atrioventricular block. Pacing Clin Electrophysiol 20(8 Pt 2):2098-2101

3. Epstein AE, DiMarco JP, Ellenbogen KA, Estes NA 3rd, Freedman RA, Gettes LS, Gillinov AM, Gregoratos G, Hammill SC, Hayes DL, Hlatky MA et al (2008) ACC/AHA/HRS 2008 guidelines for device-based therapy of cardiac rhythm abnormalities: a report of the American college of cardiology/american heart association task force on practice guidelines. J Am Coll Cardiol 51(21):e1-e62

4. Prinzen FW, Peschar M (2002) Relation between the pacing induced sequence of activation and left ventricular pump function in animals. Pacing Clin Electrophysiol 25(4 Pt 1):484-498

5. Moak JP, Barron KS, Hougen TJ, Wiles HB, Balaji S, Sreeram N, Cohen MH, Nordenberg A, Van Hare GF, Friedman RA, Perez M, Cecchin F, Schneider DS, Nehgme RA, Buyon JP (2001) Congenital heart block: development of late-onset cardiomyopathy, a previously underappreciated sequela. J Am Coll Cardiol 37(1): 238-242

6. Tantengco MV, Thomas RL, Karpawich PP (2001) Left ventricular dysfunction after long-term right ventricular apical pacing in the young. J Am Coll Cardiol 37(8):2093-2100

7. Karpawich PP (2004) Chronic right ventricular pacing and cardiac performance: the pediatric perspective. Pacing Clin Electrophysiol 27(6 Pt 2):844-849

8. Thambo JB, Bordachar P, Garrigue S, Lafitte S, Sanders P, Reuter S, Girardot R, Crepin D, Reant P, Roudaut R, Jais P, Haissaguerre M, Clementy J, Jimenez M (2004) Detrimental ventricular remodeling in patients with congenital complete heart block and chronic right ventricular apical pacing. Circulation 110(25):3766-3772

9. Janousek J, Tomek V, Chaloupecky V, Gebauer RA (2004) Dilated cardiomyopathy associated with dual-chamber pacing in infants: improvement through either left ventricular cardiac resynchronization or programming the pacemaker off allowing intrinsic normal conduction. J Cardiovasc Electrophysiol 15(4): 470-474

10. Kim JJ, Friedman RA, Eidem BW, Cannon BC, Arora G, Smith EO, Fenrich AL, Kertesz NJ (2007) Ventricular function and long-term pacing in children with congenital complete atrioventricular block. J Cardiovasc Electrophysiol 18(4):373-377

11. Karpawich PP, Rabah R, Haas JE (1999) Altered cardiac histology following apical right ventricular pacing in patients with congenital atrioventricular block. Pacing Clin Electrophysiol 22(9):1372-1377

12. Gebauer RA, Tomek V, Salameh A, Marek J, Chaloupecky V, Gebauer R, Matejka T, Vojtovic P, Janousek J (2009) Predictors of left ventricular remodelling and failure in right ventricular pacing in the young. Eur Heart J 30(9):1097-1104

13. Prinzen FW, Augustijn CH, Arts T, Allessie MA, Reneman RS (1990) Redistribution of myocardial fiber strain and blood flow by asynchronous activation. Am J Physiol 259(2 Pt 2):H300 H308

14. van Oosterhout MF, Prinzen FW, Arts T, Schreuder JJ, Vanagt WY, Cleutjens JP, Reneman RS (1998) Asynchronous electrical activation induces asymmetrical hypertrophy of the left ventricular wall. Circulation 98(6):588-595

15. Prinzen FW, Hunter WC, Wyman BT, McVeigh ER (1999) Mapping of regional myocardial strain and work during ventricular pacing: experimental study using magnetic resonance imaging tagging. J Am Coll Cardiol 33(6):1735-1742

16. van Oosterhout MF, Arts T, Bassingthwaighte JB, Reneman RS, Prinzen FW (2002) Relation between local myocardial growth and blood flow during chronic ventricular pacing. Cardiovasc Res 53(4):831-840

17. Vanagt WY, Verbeek XA, Delhaas T, Mertens L, Daenen WJ, Prinzen FW (2004) The left ventricular apex is the optimal site for pediatric pacing. Pacing Clin Electrophysiol 27(6P2):837-843

18. Manolis AS (2006) The deleterious consequences of right ventricular apical pacing: time to seek alternate site pacing. Pacing Clin Electrophysiol 29(3):298-315

19. Little WC, Reeves RC, Arciniegas J, Katholi RE, Rogers EW (1982) Mechanism of abnormal interventricular septal motion during delayed left ventricular activation. Circulation 65(7): 1486-1491

20. Vatasescu R, Shalganov T, Paprika D, Kornyei L, Prodan Z, Bodor G, Szatmari A, Szili-Torok T (2007) Evolution of left ventricular function in paediatric patients with permanent right ventricular pacing for isolated congenital heart block: a medium term follow-up. Europace 9(4):228-232

21. Shalganov TN, Paprika D, Vatasescu R, Kardos A, Mihalcz A, Kornyei L, Szatmari A, Szili-Torok T (2007) Mid-term echocardiographic follow up of left ventricular function with permanent right ventricular pacing in pediatric patients with and without structural heart disease. Cardiovasc Ultrasound 5:13

22. Karpawich PP, Mital S (1997) Comparative left ventricular function following atrial, septal, and apical single chamber heart pacing in the young. Pacing Clin Electrophysiol 20(8 Pt 1): 1983-1988

23. Deshmukh P, Casavant DA, Romanyshyn M, Anderson K (2000) Permanent, direct His-bundle pacing: A novel approach to cardiac pacing in patients with normal His-Purkinje activation. Circulation 101(8):869-877

24. Deshmukh PM, Romanyshyn M (2004) Direct his-bundle pacing: present and future. Pacing Clin Electrophysiol 27(6 Pt 2):862-870

25. Zanon F, Baracca E, Aggio S, Pastore G, Boaretto G, Cardano P, Marotta T, Rigatelli G, Galasso M, Carraro M, Zonzin P (2006) A feasible approach for direct his-bundle pacing using a new steerable catheter to facilitate precise lead placement. J Cardiovasc Electrophysiol 17(1):29-33

26. Hillock RJ, Stevenson IH, Mond HG (2007) The right ventricular outflow tract: a comparative study of septal, anterior wall, and free wall pacing. Pacing Clin Electrophysiol 30(8):942-947

27. Mond HG, Hillock RJ, Stevenson IH, McGavigan AD (2007) The right ventricular outflow tract: the road to septal pacing. Pacing Clin Electrophysiol 30(4):482-491

28. de Cock CC, Giudici MC, Twisk JW (2003) Comparison of the haemodynamic effects of right ventricular outflow-tract pacing with right ventricular apex pacing: a quantitative review. Europace 5(3):275-278

29. Albouaini K, Alkarmi A, Mudawi T, Gammage MD, Wright DJ (2009) Selective site right ventricular pacing. Heart 95(24): 2030-2039 
30. Cowell R, Morris-Thurgood J, Ilsley C, Paul V (1994) Septal short atrioventricular delay pacing: additional hemodynamic improvements in heart failure. Pacing Clin Electrophysiol 17(11 Pt 2):1980-1983

31. Mera F, DeLurgio DB, Patterson RE, Merlino JD, Wade ME, Leon AR (1999) A comparison of ventricular function during high right ventricular septal and apical pacing after His-bundle ablation for refractory atrial fibrillation. Pacing Clin Electrophysiol 22(8):1234-1239

32. Schwaab B, Frohlig G, Alexander C, Kindermann M, Hellwig N, Schwerdt H, Kirsch CM, Schieffer H (1999) Influence of right ventricular stimulation site on left ventricular function in atrial synchronous ventricular pacing. J Am Coll Cardiol 33(2): 317-323

33. Tse HF, Yu C, Wong KK, Tsang V, Leung YL, Ho WY, Lau CP (2002) Functional abnormalities in patients with permanent right ventricular pacing: the effect of sites of electrical stimulation. J Am Coll Cardiol 40(8):1451-1458

34. Victor F, Mabo P, Mansour H, Pavin D, Kabalu G, de Place C, Leclercq C, Daubert JC (2006) A randomized comparison of permanent septal versus apical right ventricular pacing: shortterm results. J Cardiovasc Electrophysiol 17(3):238-242

35. Occhetta E, Bortnik M, Magnani A, Francalacci G, Piccinino C, Plebani L, Marino P (2006) Prevention of ventricular desynchronization by permanent para-Hisian pacing after atrioventricular node ablation in chronic atrial fibrillation: a crossover, blinded, randomized study versus apical right ventricular pacing. J Am Coll Cardiol 47(10):1938-1945

36. St John Sutton MG, Plappert T, Abraham WT, Smith AL, DeLurgio DB, Leon AR, Loh E, Kocovic DZ, Fisher WG, Ellestad M, Messenger J, Kruger K, Hilpisch KE, Hill MR (2003) Effect of cardiac resynchronization therapy on left ventricular size and function in chronic heart failure. Circulation 107(15):1985-1990

37. Daubert JC, Leclercq C, Donal E, Mabo P (2006) Cardiac resynchronisation therapy in heart failure: current status. Heart Fail Rev 11(2):147-154

38. Linde C, Abraham WT, Gold MR, St John Sutton M, Ghio S, Daubert C (2008) Randomized trial of cardiac resynchronization in mildly symptomatic heart failure patients and in asymptomatic patients with left ventricular dysfunction and previous heart failure symptoms. J Am Coll Cardiol 52(23):1834-1843

39. Leclercq C, Cazeau S, Lellouche D, Fossati F, Anselme F, Davy JM, Sadoul N, Klug D, Mollo L, Daubert JC (2007) Upgrading from single chamber right ventricular to biventricular pacing in permanently paced patients with worsening heart failure: the rdchf study. Pacing Clin Electrophysiol 30 Suppl 1:S23-S30

40. Laurenzi F, Achilli A, Avella A, Peraldo C, Orazi S, Perego GB, Cesario A, Valsecchi S, De Santo T, Puglisi A, Tondo C (2007) Biventricular upgrading in patients with conventional pacing system and congestive heart failure: results and response predictors. Pacing Clin Electrophysiol 30(9):1096-1104

41. van Geldorp IE, Vernooy K, Delhaas T, Prins MH, Crijns HJ, Prinzen FW, Dijkman B (2010) Beneficial effects of biventricular pacing in chronically right ventricular paced patients with mild cardiomyopathy. Europace 12(2):223-229

42. Shimano M, Tsuji Y, Yoshida Y, Inden Y, Tsuboi N, Itoh T, Suzuki H, Muramatsu T, Okada T, Harata S, Yamada T, Hirayama H, Nattel S, Murohara T (2007) Acute and chronic effects of cardiac resynchronization in patients developing heart failure with long-term pacemaker therapy for acquired complete atrioventricular block. Europace 9(10):869-874

43. Dubin AM, Janousek J, Rhee E, Strieper MJ, Cecchin F, Law IH, Shannon KM, Temple J, Rosenthal E, Zimmerman FJ, Davis A, Karpawich PP, Al Ahmad A, Vetter VL, Kertesz NJ, Shah M, Snyder C, Stephenson E, Emmel M, Sanatani S, Kanter R, Batra A, Collins KK (2005) Resynchronization therapy in pediatric and congenital heart disease patients: an international multicenter study. J Am Coll Cardiol 46(12):2277-2283

44. Janousek J, Gebauer RA, Abdul-Khaliq H, Turner M, Kornyei L, Grollmuss O, Rosenthal E, Villain E, Fruh A, Paul T, Blom NA, Happonen JM, Bauersfeld U, Jacobsen JR, van den Heuvel F, Delhaas T, Papagiannis J, Trigo C (2009) Cardiac resynchronisation therapy in paediatric and congenital heart disease: differential effects in various anatomical and functional substrates. Heart 95(14):1165-1171

45. Janousek J, Gebauer RA (2008) Cardiac resynchronization therapy in pediatric and congenital heart disease. Pacing Clin Electrophysiol 31 Suppl 1:S21-S23

46. Wyman BT, Hunter WC, Prinzen FW, Faris OP, McVeigh ER (2002) Effects of single- and biventricular pacing on temporal and spatial dynamics of ventricular contraction. Am J Physiol Heart Circ Physiol 282(1):H372-H379

47. Peschar M, de Swart H, Michels KJ, Reneman RS, Prinzen FW (2003) Left ventricular septal and apex pacing for optimal pump function in canine hearts. J Am Coll Cardiol 41(7):1218-1226

48. Vanagt WY, Prinzen FW, Delhaas T (2007) Reversal of pacinginduced heart failure by left ventricular apical pacing. N Engl J Med 357(25):2637-2638

49. Tomaske M, Breithardt OA, Balmer C, Bauersfeld U (2009) Successful cardiac resynchronization with single-site left ventricular pacing in children. Int J Cardiol 136(2):136-143

50. Mills RW, Cornelussen RN, Mulligan LJ, Strik M, Rademakers LM, Skadsberg ND, van Hunnik A, Kuiper M, Lampert A, Delhaas T, Prinzen FW (2009) Left ventricular septal and left ventricular apical pacing chronically maintain cardiac contractile coordination, pump function and efficiency. Circ Arrhythm Electrophysiol 2(5):571-579

51. Auricchio A (2004) Pacing the left ventricle: does underlying rhythm matter? J Am Coll Cardiol 43(2):239-240

52. Etienne Y, Mansourati J, Gilard M, Valls-Bertault V, Boschat J, Benditt DG, Lurie KG, Blanc JJ (1999) Evaluation of left ventricular based pacing in patients with congestive heart failure and atrial fibrillation. Am J Cardiol 83(7):1138-1140, A1139

53. Touiza A, Etienne Y, Gilard M, Fatemi M, Mansourati J, Blanc JJ (2001) Long-term left ventricular pacing: assessment and comparison with biventricular pacing in patients with severe congestive heart failure. J Am Coll Cardiol 38(7):1966-1970

54. Puggioni E, Brignole M, Gammage M, Soldati E, Bongiorni MG, Simantirakis EN, Vardas P, Gadler F, Bergfeldt L, Tomasi C, Musso G, Gasparini G, Del Rosso A (2004) Acute comparative effect of right and left ventricular pacing in patients with permanent atrial fibrillation. J Am Coll Cardiol 43(2):234-238

55. van Geldorp IE, Vanagt WY, Bauersfeld U, Tomaske M, Prinzen FW, Delhaas T (2009) Chronic left ventricular pacing preserves left ventricular function in children. Pediatr Cardiol 30(2):125-132

56. Gebauer RA, Tomek V, Kubus P, Razek V, Matejka T, Salameh A, Kostelka M, Janousek J (2009) Differential effects of the site of permanent epicardial pacing on left ventricular synchrony and function in the young: implications for lead placement. Europace 11(12):1654-1659

57. Dodge-Khatami A, Kadner A, Dave H, Rahn M, Pretre R, Bauersfeld U (2005) Left heart atrial and ventricular epicardial pacing through a left lateral thoracotomy in children: a safe approach with excellent functional and cosmetic results. Eur J Cardiothorac Surg 28(4):541-545

58. Tomaske M, Breithardt OA, Bauersfeld U (2009) Preserved cardiac synchrony and function with single-site left ventricular epicardial pacing during mid-term follow-up in paediatric patients. Europace 11(9):1168-1176

59. van Geldorp IE, Janousek J, Gebauer R, Vanagt W, Prinzen FW, Delhaas T (2009) LV pacing is superior to RV pacing in children with AV block: a multi-center study. Circulation 120(18S):S714 
60. Janousek J, van Geldorp IE, Prinzen FW, Vanagt WY, Elders J, Fruh A, Kubus P, Tomaske M, Ganame J, Nagel B, Papagiannis J, Wren C, Nurnberg JH, Delhaas T, Gebauer RA (2010) LV pacing preserves ventricular synchrony and function in children with AV block and structurally normal heart as compared to RV pacing sites: a multi-center study. Heart Rhythm 7(5S):S6

61. Dubin AM, Feinstein JA, Reddy VM, Hanley FL, Van Hare GF, Rosenthal DN (2003) Electrical resynchronization: a novel therapy for the failing right ventricle. Circulation 107(18):2287-2289

62. Stephenson EA, Cecchin F, Alexander ME, Triedman JK, Walsh EP, Berul CI (2004) Relation of right ventricular pacing in Tetralogy of Fallot to electrical resynchronization. Am J Cardiol 93(11):1449-1452, A1412

63. Byrne MJ, Helm RH, Daya S, Osman NF, Halperin HR, Berger RD, Kass DA, Lardo AC (2007) Diminished left ventricular dyssynchrony and impact of resynchronization in failing hearts with right versus left bundle branch block. J Am Coll Cardiol 50(15):1484-1490

64. Bordachar P, Iriart X, Chabaneix J, Sacher F, Lafitte S, Jais P, Haissaguerre M, Clementy J, Dos Santos P, Thambo JB (2008) Presence of ventricular dyssynchrony and haemodynamic impact of right ventricular pacing in adults with repaired Tetralogy of Fallot and right bundle branch block. Europace 10(8):967-971

65. Thambo JB, Dos Santos P, De Guillebon M, Roubertie F, Labrousse L, Sacher F, Iriart X, Lafitte S, Ploux S, Jais P, Roques X, Haissaguerre M, Ritter P, Clementy J, Narayan SM, Bordachar P (2010) Biventricular stimulation improves right and left ventricular function after tetralogy of fallot repair: acute animal and clinical studies. Heart Rhythm 7(3):344-350

66. Delhaas T, Prinzen FW (2010) Right ventricular or biventricular pacing in repaired Tetralogy of Fallot? Heart Rhythm 7(3): 351-352

67. Prinzen FW, Van Oosterhout MF, Vanagt WY, Storm C, Reneman RS (1998) Optimization of ventricular function by improving the activation sequence during ventricular pacing. Pacing Clin Electrophysiol 21(11 Pt 2):2256-2260
68. Zimmerman FJ, Starr JP, Koenig PR, Smith P, Hijazi ZM, Bacha EA (2003) Acute hemodynamic benefit of multisite ventricular pacing after congenital heart surgery. Ann Thorac Surg 75(6): $1775-1780$

69. Ramanathan C, Ghanem RN, Jia P, Ryu K, Rudy Y (2004) Noninvasive electrocardiographic imaging for cardiac electrophysiology and arrhythmia. Nat Med 10(4):422-428

70. Silva JN, Ghosh S, Bowman TM, Rhee EK, Woodard PK, Rudy Y (2009) Cardiac resynchronization therapy in pediatric congenital heart disease: insights from noninvasive electrocardiographic imaging. Heart Rhythm 6(8):1178-1185

71. Echt DS, Cowan MW, Riley RE, Brisken AF (2006) Feasibility and safety of a novel technology for pacing without leads. Heart Rhythm 3(10):1202-1206

72. Lee KL, Tse HF, Echt DS, Lau CP (2009) Temporary leadless pacing in heart failure patients with ultrasound-mediated stimulation energy and effects on the acoustic window. Heart Rhythm 6(6):742-748

73. Nielsen JC, Kristensen L, Andersen HR, Mortensen PT, Pedersen OL, Pedersen AK (2003) A randomized comparison of atrial and dual-chamber pacing in 177 consecutive patients with sick sinus syndrome: echocardiographic and clinical outcome. J Am Coll Cardiol 42(4):614-623

74. Andersen HR, Nielsen JC, Thomsen PE, Thuesen L, Mortensen PT, Vesterlund T, Pedersen AK (1997) Long-term follow-up of patients from a randomised trial of atrial versus ventricular pacing for sick-sinus syndrome. Lancet 350(9086):1210-1216

75. Batra AS, Wells WJ, Hinoki KW, Stanton RA, Silka MJ (2003) Late recovery of atrioventricular conduction after pacemaker implantation for complete heart block associated with surgery for congenital heart disease. J Thorac Cardiovasc Surg 125(6):12911293

76. Vanagt WY, Verbeek XA, Delhaas T, Gewillig M, Mertens L, Wouters P, Meyns B, Daenen WJ, Prinzen FW (2005) Acute hemodynamic benefit of left ventricular apex pacing in children. Ann Thorac Surg 79(3):932-936 